\title{
Control of Local Hardness Gradient of Metal Surface by Inclined Surface Treatment Using Ultrasonic Nanocrystal Surface Modification
}

\author{
Yeong-Kwan Jo ${ }^{1} \cdot$ Yeong-Wook Gil ${ }^{1} \cdot$ Do-Sik Shim ${ }^{2} \cdot$ Young-Sik Pyun $^{3} \cdot$ Sang-Hu Park $^{4}$ (i)
}

Received: 31 March 2020 / Revised: 28 October 2020 / Accepted: 11 December 2020 / Published online: 13 January 2021

(c) The Author(s) 2020

\begin{abstract}
We propose an effective method to control the local hardness and morphology of a metal surface by tilting the incident angle of a horn during ultrasonic nanocrystal surface modification (UNSM). In this study, surface treatment using UNSM was performed on an $\mathrm{S} 45 \mathrm{C}$ specimen and a parameter study was conducted for optimization. The process parameters were the feeding rate, static load, striking force, and processing angle $(\Phi)$. In particular, the $\Phi$ was analyzed by tilting the horn by $0^{\circ}$, $10^{\circ}, 20^{\circ}, 30^{\circ}, 40^{\circ}$, and $45^{\circ}$ to understand its effect on surface hardness and changes in the morphology. From fundamental experiments, some important phenomena were observed, such as grain-microstructure changes along the processing and thickness directions. Furthermore, to verify the practical usefulness of this study, a flat and a hemispherical specimen of S45C material were treated using UNSM with various values of $\Phi$. A significant change in hardness (an increase from 2-45\%) and a gradual hardness gradient on the tested specimens could be easily realized by the proposed method. Therefore, we believe that the method is effective for controlling the mechanical hardness of a metal surface.
\end{abstract}

Keywords Ultrasonic nanocrystal surface modification $\cdot$ Surface treatment $\cdot$ Processing angle $\cdot$ Hardness gradient

\section{Introduction}

In various fields, such as general machinery, defense, precision engineering, and automobile industries, surface treatment is performed to increase the wear and corrosion resistance of parts. Generally, surface treatment can be classified into chemical and physical surface treatment methods [1, 2]. The chemical surface treatment method includes plating processes [3-5], nitriding treatments [6-8], and chemical vapor deposition [9-11]. These chemical surface treatment methods are widely used owing to their ease and mass productivity in various industries. However, chemical surface

Sang-Hu Park

sanghu@pusan.ac.kr

1 Graduate School of Mechanical Engineering, Pusan National University, Busan 46241, Korea

2 Division of Mechanical Engineering-Major of Marine Equipment, Korea Maritime and Ocean University, Busan 49112, Korea

3 School of Mechanical Engineering, Sunmoon University, Asan-si, Chungcheongnam-do 31460, Korea

4 School of Mechanical Engineering, Pusan National University, Busan 46241, Korea treatments cause the environmental pollution of chemical materials such as electrolytes and require large-scale special equipment and complicated processes. Additionally, surface treatment cannot be easily performed both locally and partially.

The physical surface treatment method includes shot peening [12-15], laser peening [16-21], heat treatment [22-26], and ultrasonic nanocrystal surface modification (UNSM) [27-30]. These processes are eco-friendly compared with chemical treatment processes and require short processing times; therefore, they are utilized to improve the mechanical properties of molds, bearing races, shafts, rollers, and many other mechanical parts. Among these methods, shot peening, which has been reported by Menezes et al., showed improvement in hardness by more than $30 \%$ of that of AISI 316L stainless steel surface, to which plasma carburizing and nitriding were applied [12]. González et al. applied shot peening to increase the surface wear and corrosion resistance of white cast iron alloys, through which they improved the wear resistance by $20 \%$ [13]. Avcu et al. studied the use of shot peening and reported an improvement in wear resistance of approximately $20 \%$ in Ti6 Al4V alloys [14]. Furthermore, Zhou et al. studied the effect of laser assisted shot peening on the wear and tribological behavior 
of medical Ti6Al4V alloys and improved their wear resistance of $30 \%$ [17]. Yin et al. applied laser peening on the surface of Ti-6Al-4V alloy and improved the impact wear characteristics by approximately $44 \%$ [18]. Dai et al. used both soft and hard contact laser shock peening and improved surface hardness by approximately $10 \%$ [19]. Ge et al.. studied the surface wear characteristics of the surface laser shock peening of $\mathrm{Mg}-3 \mathrm{Al}-1 \mathrm{Zn}$ alloy to improve the surface wear resistance by up to $70 \%$ [20]. Although laser peening can enable a higher hardness and the wear-proof characteristics of metal surfaces, the equipment involved is expensive.

However, UNSM is well known as eco-friendly and enables a regional surface treatment with smaller and relative low-price equipment than other methods [27-30]. To improve wear resistance using UNSM, Tripathi et al. studied the hybrid use of UNSM and laser surface texturing processes to improve the friction and wear performance of cast iron engine cylinders and enhanced the wear resistance by $65 \%$ [27]. In another study pertaining to the microstructure and characteristics of the laminated NiTi alloys, the amount of wear reduced by approximately 44\% after UNSM [28]. In addition, many studies have been conducted to improve wear resistance through UNSM [29, 30]. In most studies, a surface with uniform hardness was obtained by processing at the right incident angle of a horn in UNSM. The hardness and morphology of UNSM-treated surfaces are affected by the energy input. Comparing with the normal UNSM process through vertical strikes reported in the previous studies [27-30], the proposed method with controlling the angle of incidence of a horn has an important advantage to increase the local surface hardness adaptively for wear resistance. The change of incidence angle is controllable and it is easily applied to arbitrary shape of diverse metal surfaces. Using this simple idea, we generated a metal surface having a wide range of hardness locally. Furthermore, we analyzed the microstructure changes of the treated surface.

\section{Experimental Section}

\subsection{UNSM}

In UNSM, a metallic horn strikes on a target surface 1,000 to 10,000 times per $\mathrm{mm}^{2}$ with static and dynamic loads applied by ultrasonic vibration conditions of $20,000 \mathrm{~Hz}$, thereby generating severe plastic and elastic deformation on the local area. Moreover, an affected layer is formed in the thickness with grain refinement and large compressive residual stress. Generally, the deformed layer is several micrometers in thickness, which can be controlled by the process parameters of UNSM. After this process, the strength and hardness of the treated surface will be significantly improved. Figures 1a, b show the experimental setup for UNSM, the definition of the processing angle, and the effect on grain refinement. Additionally, the inset of Fig. 1b shows a scanning electron microscope (SEM) image captured by MIRA3 (Tescan, Czech) after UNSM, showing coarse grain structures transforming into fine ones in the deformed layer thickness $\left(T_{D L}\right)$. The change in the microstructure was caused a severe plastic deformation zone generated near the skin through the high load and vibration strikes on the metal surface [30].

The $T_{D}$ ranged of 40 to $60 \mu \mathrm{m}$ and can be changed by the processing parameters, such as the striking force, overlapping gap, and duration time. The basic system of UNSM, as shown in Fig. 1a, comprises a generator, which generates ultrasonic frequencies; a ballast weight that is equal to a static load; a transducer for generating mechanical ultrasonic waves; a booster for amplifying waves; a horn that delivers the amplified ultrasonic waves without loss; and a tungsten carbide ball of diameter $2.4 \mathrm{~mm}$ at the end of a horn for striking the target surface with ultrasonic vibration energy. A UNSM equipment was installed to a commercial computerized numerical control (CNC) machining center (V55, Makino, Japan) for controlling and processing. Subsequently, the process parameters for surface treatment were studied to apply the surface treatment to $\mathrm{S} 45 \mathrm{C}$ material. The interval and ultrasonic frequency were fixed at $0.05 \mathrm{~mm} / \mathrm{rev}$ and $2 \mathrm{kHz}$, respectively, and the feed rate and loading force were adjusted to optimize the process conditions. Three different feeding rates of 1500, 2000, and $2500 \mathrm{~mm} / \mathrm{min}$ and three static loading forces of 1,3 , and $5 \mathrm{kgf}$ were evaluated.

\subsection{Effects of Processing Angle, $\Phi$}

In this study, an experiment was conducted to analyze the effects of surface treatment with varying processing angles $(\Phi)$; the processing angle is defined as the incident angle of the horn, as depicted in Fig. 1b. A test specimen was fixed on a working table by fixtures, and the UNSM equipment was setup with a certain angle of $\Phi$ in a CNC machining center. The processing angle, $\Phi$ was defined as zero degree when the horn was set perpendicular to the surface of a test specimen. A zero value of $\Phi$ is a reference angle to the other cases, and it is the typically used value for UNSM. Furthermore, $\Phi$ can be controlled by tilting the UNSM equipment in a CNC machining center. Additionally, the maximum force applied to the metal surface can be calculated as shown in Eq. (1), where $\Phi$ is zero [29]:

$F_{i n}=P_{s t}+P_{d y}=P_{s t}+P_{a m p} \sin (2 \pi f t)$

Here, $F_{\text {in }}(\mathrm{N})$ is the total striking load; $P_{s t}(\mathrm{~N})$ is the static normal load provided by the weight of the ballast shown in Fig. 1; $P_{d y}(\mathrm{~N})$ is the dynamic load controlled by the input of the frequency; $P_{\text {amp }}(\mathrm{N})$ is the amplitude of the dynamic 


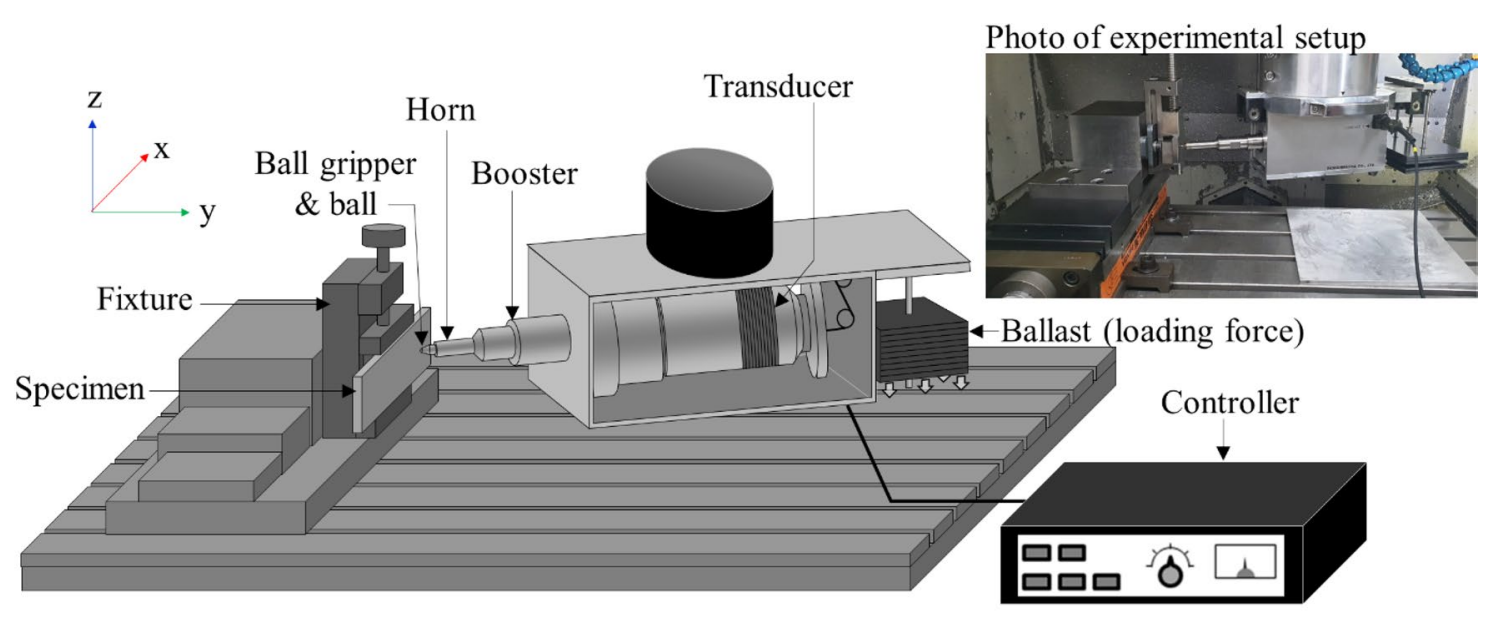

(a)
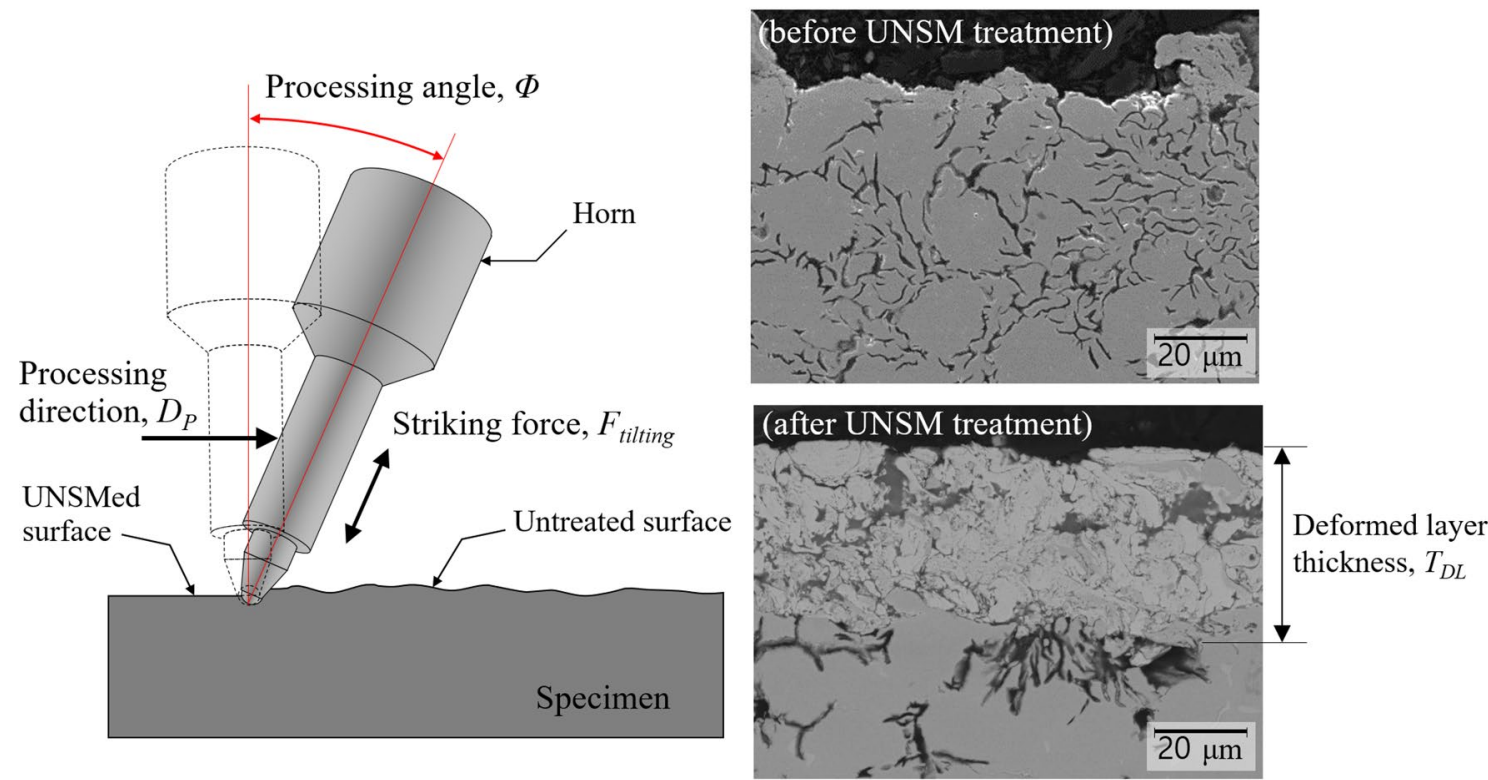

(b)

Fig. 1 a Experimental setup of ultrasonic nanocrystal surface modification (UNSM) process, and b definition of processing angle, $\Phi$ (left), grain refinement by UNSM treatment (SEM image) (right); deformed layer thickness $\left(T_{D L}\right)$ was $40-60 \mu \mathrm{m}$ according to processing conditions

load, which is a system parameter and is assumed to be a fixed value of $20 \mathrm{~N} ; f(\mathrm{~Hz})$ is the frequency of input; $t(\mathrm{~s})$ is the treatment duration. In the case of non-zero $\Phi$, the total normal striking load can be expressed as Eq. (2) in terms of the tilting processing angle $\Phi$ :

$F_{\text {tilting }}=F_{\text {in }} \cdot \cos \Phi=P_{s t} \cdot \cos \Phi+P_{\text {amp }} \sin (2 \pi f t) \cdot \cos \Phi$,

From Eq. (2), the total striking force $\left(F_{\text {tilting }}\right)$ on the surface can be calculated according to the processing angle, which is shown in Fig. 2. In the calculation, $P_{s t}$ was $5 \mathrm{kgf}$, $f$ was $20 \mathrm{kHz}$, and $t$ was between 0 and 2400s. During the time, the maximum force was obtained using Eq. (2). The striking force decreased rapidly by an increase in $\Phi$. Comparing the forces at zero $\Phi$ (vertical loading condition) and $20^{\circ} \Phi, F_{\text {tilting }}$ was decreased by approximately $6.0 \%$; however, the processing angle $\Phi$ was larger than $20^{\circ}$, and $F_{\text {tilting }}$ decreased rapidly and continually. When $\Phi$ reached $45^{\circ}, F_{\text {tilting }}$ was reduced by approximately $30.7 \%$ compared with the largest one (zero $\Phi$ condition). The 


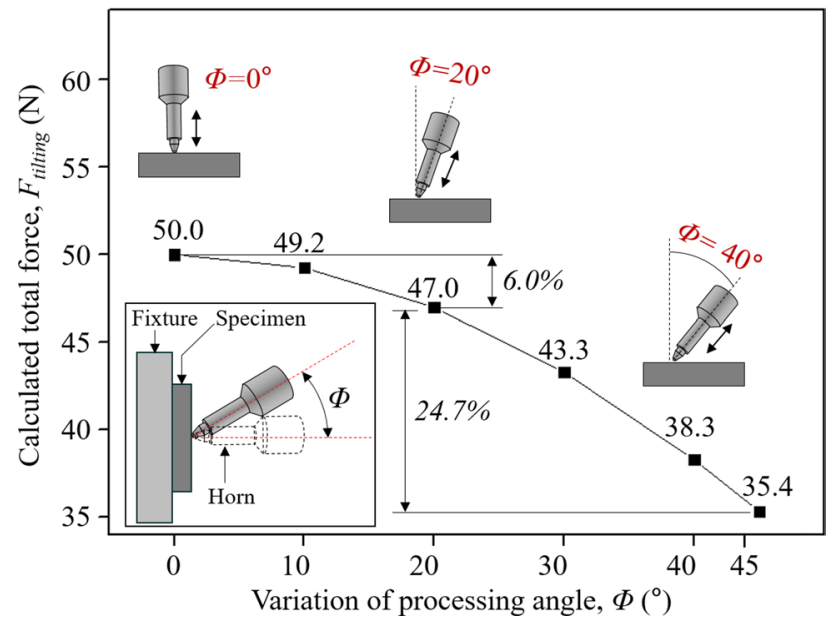

Fig. 2 Variation in normal striking force $\left(F_{\text {tilting }}\right)$ at the surface according to processing angle $\Phi$ from $0^{\circ}$ to $45^{\circ}$. The total force changed slightly at $\Phi$ ranging from $0^{\circ}$ to $20^{\circ}$. In large angles $\Phi$ exceeding $30^{\circ}, F_{\text {tilting }}$ reduced significantly

increase of hardness was affected by the amount of normal striking load, $F_{\text {tilting }}$. The surface was plastically deformed by UNSM, which yielded fine grains; moreover, it was work hardened, causing increased hardness [31]. Therefore, we believe that the hardness of the treated surface can be controlled by changing the normal striking load, which depends on the processing angle.

\section{Results and Discussion}

\subsection{Control of Surface Hardness}

To control the surface hardness by changing the processing angle $\Phi$, we conducted UNSM at several processing angles of $\Phi$, i.e., $0^{\circ}, 10^{\circ}, 20^{\circ}, 30^{\circ}, 40^{\circ}$, and $45^{\circ}$. The processing angle was controlled within a range of $\pm 0.1^{\circ}$. The surface hardness was measured at 20 points on a treated surface with a gap of $50 \mu \mathrm{m}$ along the processing direction $\left(D_{P}\right)$; additionally, the hardness at 10 points along the thickness direction $\left(D_{T}\right)$ was measured with a gap of 50 and $70 \mu \mathrm{m}$ perpendicular to each other, as depicted in Fig. 3. A microhardness tester (HM-112, Mituyoto, Japan) was utilized to measure the hardness with a load of $0.1 \mathrm{kgf}$. To understand the effect of the process parameters, we performed a basic study, as shown in Table 1. Using nine cases of different surface treatment conditions on a S45C plate measuring $10 \mathrm{~mm}$ in thickness, we evaluated four process parameters: the static load, $P_{s t}(10,30$, and $50 \mathrm{~N})$, feed rate, $v_{f}(1500,2000$, and $2500 \mathrm{~mm} / \mathrm{min})$, line interval, $d_{f}(50 \mu \mathrm{m})$, and frequency, $f$ $(20 \mathrm{kHz})$, and determined the dominant parameter affecting the hardness change. The measured results of hardness are summarized in Table 1. A higher static load and a smaller feed rate affected the increase in the surface hardness more significantly than other cases owing to the higher energy input per unit area on the specimen. The largest hardness of $384.3 \mathrm{Hv}$ was obtained under the processing conditions of Case-7, and the smallest one was 257.6 Hv under Case-3.
Fig. 3 Measurement points of hardness along processing and thickness direction $\left(D_{P}\right.$ and $D_{T}$, respectively). Hardness was measured with a gap of $50 \mu \mathrm{m}$ along the direction of $D_{P}$ and with gaps of 50 and $70 \mu \mathrm{m}$ (in each horizontal and vertical distance) along the thickness direction, $D_{T}$. The inset shows an indentation mark of the hardness measurement; its width was approximately $17.1 \mu \mathrm{m}$

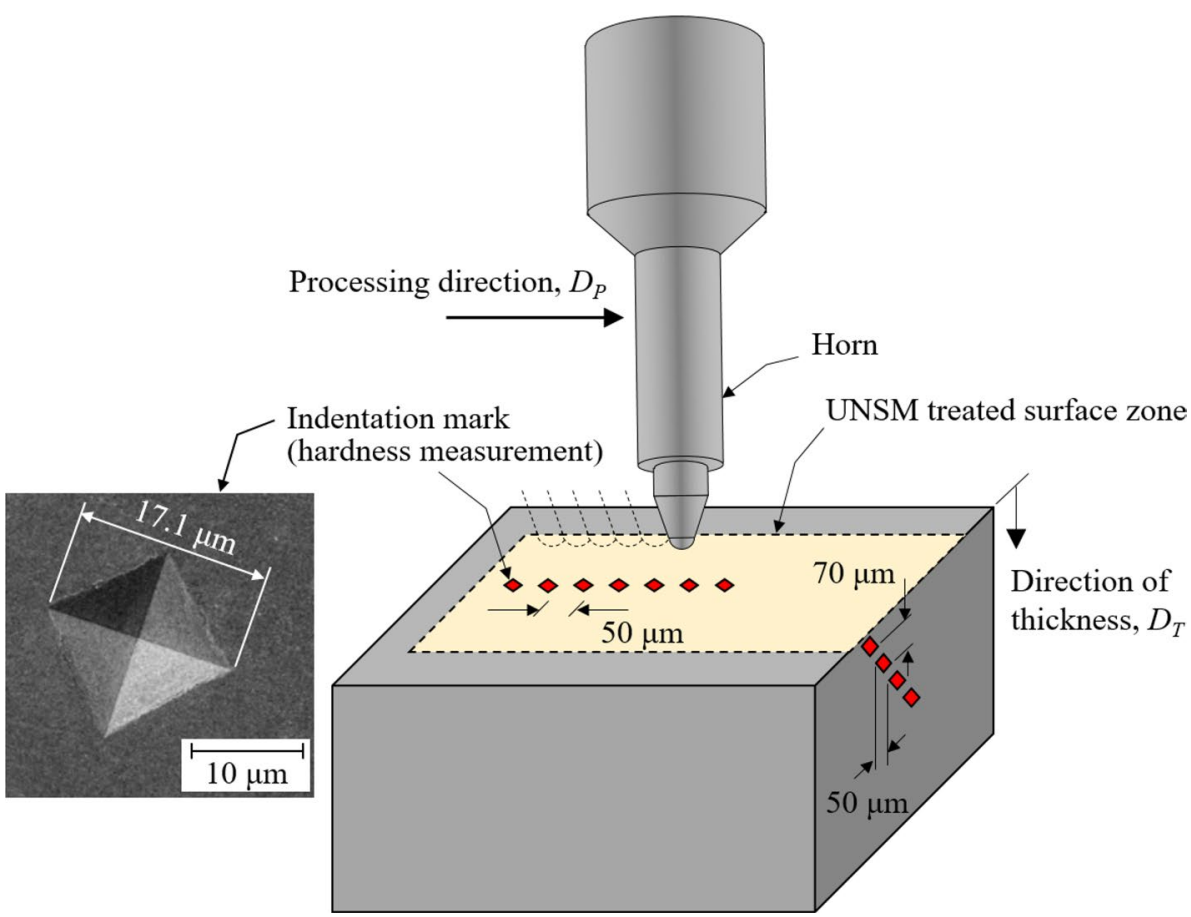


Table 1 Results of hardness measurement on surface under various process parameters

\begin{tabular}{|c|c|c|c|c|c|c|}
\hline \multirow[t]{2}{*}{ Case no. } & \multicolumn{4}{|c|}{ Process parameters } & \multirow[t]{2}{*}{ Description of UNSM parameters } & \multirow[t]{2}{*}{ Hardness(Hv) } \\
\hline & $\begin{array}{l}\text { Static load,P } \mathrm{P}_{\mathrm{st}} \\
(\mathrm{N})\end{array}$ & $\begin{array}{l}\text { Feed rate, } \\
\mathrm{v}_{\mathrm{f}}(\mathrm{mm} / \mathrm{min})\end{array}$ & $\begin{array}{l}\text { Interval, } \\
d_{f}(\mu \mathrm{m})\end{array}$ & $\begin{array}{l}\text { Frequency, } \\
\mathrm{f}(\mathrm{kHz})\end{array}$ & & \\
\hline 1 & 10 & 1500 & 50 & 20 & $s t$ & 281.3 \\
\hline 2 & 10 & 2000 & & & & 269.9 \\
\hline 3 & 10 & 2500 & & & & 257.6 \\
\hline 4 & 30 & 1500 & & & & 332.4 \\
\hline 5 & 30 & 2000 & & & & 310.8 \\
\hline 6 & 30 & 2500 & & & & 293.1 \\
\hline 7 & 50 & 1500 & & & & 384.3 \\
\hline 8 & 50 & 2000 & & & & 354.7 \\
\hline 9 & 50 & 2500 & & & & 311.4 \\
\hline
\end{tabular}

Compared with the initial hardness of S45C, i.e., approximately $214.5 \mathrm{Hv}$, it increased to $49.2 \%$ under the best condition. The UNSM parameters obtained experimentally were as follows; $P_{s t}$ of $50 \mathrm{~N}, v_{f}$ of $1500 \mathrm{~mm} / \mathrm{min}, d_{f}$ of $50 \mu \mathrm{m}$, and $f$ of $20 \mathrm{kHz}$, and these conditions were utilized to analyze the effect of the processing angle, $\Phi$.

The measured hardness after surface treatment according to various $\Phi$ is shown in Fig. 4a. The surface hardness was controlled by changing $\Phi$; it increased significantly to $79 \%$ $(384.3 \mathrm{Hv}$ ) at zero $\Phi$ and only to $2 \%(218.2 \mathrm{Hv})$ at a $\Phi$ of $45^{\circ}$ compared with the initial hardness of the S45C material. When the $\Phi$ increased to more than $30^{\circ}$, the rate of increase in hardness decelerated. Therefore, two districts were identified, each having an inclination of Slope- $a\left(2.17 \mathrm{Hv} /^{\circ}\right)$ and $-b\left(6.72 \mathrm{Hv} /{ }^{\circ}\right)$; they were distinguished at a critical $\Phi$ of $30^{\circ}$. This can be explained using Fig. 2 . The striking force, $F_{\text {tilting }}$ was reduced to $13.4 \%$ compared with the two $\Phi$ values of $0^{\circ}$ and $30^{\circ}$; however, its value increased to $18.2 \%$ between a $\Phi$ of $30^{\circ}$ and $45^{\circ}$. Assuming that the inclination of force variation was linear, the decreasing rates of $F_{\text {tilting }}$ in each district were 0.22 and $0.446 \mathrm{~N} /{ }^{\circ}$. Comparing the force change rate between the two districts, that of the second district was approximately 2.4 times larger. Furthermore, Slope- $b$, which indicated a hardness variation rate in Range- $b$ of Fig. 4a, was larger 3.1 times than Slope-a. Therefore, the force change was similar to the change in hardness; hence, the hardness can be controlled by changing the processing angle $\Phi$.

To evaluate the effect of UNSM along the thickness direction $\left(D_{T}\right)$, we measured the hardness change by cutting the cross section of the specimen, as shown in Fig. 4b. Based on the $D_{T}$, we discovered that the treatment was effective up to approximately $330 \mu \mathrm{m}$ at the $\Phi$ from $0^{\circ}$ to $30^{\circ}$ and up to approximately $280 \mu \mathrm{m}$ at the $\Phi$ of $40^{\circ}$ and $45^{\circ}$. This phenomenon indicates that the energy applied to the surface decreases significantly as in the force, which is depicted in Fig. 2, and decreases according to the increase in $\Phi$. That is, the insufficient force applied to the surface may not reform the microstructures of the material. Based on these results, we expect the surface characteristics to be modifiable by the gradient control of hardness along the thickness direction.

\subsection{Roughness and Microstructure}

The surface roughness after UNSM was measured using an equipment (Form Talysurf Series-2, Taylor Hobson Co., U.K.) along two directions, $D_{P}$ and $D_{V}$, i.e., the processing direction and its perpendicular direction, respectively (see the inset of Fig. 5a). The surface roughness increased continuously with the increase in the processing angle $\Phi$; in particular, the roughness along $D_{V}$ was much higher than that of $D_{P}$ owing to the wavy pattern generated by multiple repeated tool-paths, as depicted in Fig. 5a. Generally, the surface roughness after UNSM with $\Phi=0^{\circ}$ improves compared with the initial state [27-29]. However, to be more exact, $h$ roughness is typically improved along the processing direction; perpendicular to the processing direction, the surface is slightly rougher or similar owing to the generated wavy patterns even though UNSM is performed 
Fig. 4 Measurement data of hardness distribution: a hardness change on a surface by processing angle $\Phi$; the inclination of the hardness variation changed rapidly when $\Phi$ was larger than $30^{\circ}$ (see Slopes- $a$ and $-b$ ), and $\mathbf{b}$ hardness variation along thickness direction from the surface; $D_{T}$ was obtained by measuring the hardness on the cross section of a specimen. The deformed layer thicknesses $\left(T_{D L}\right)$ of two categories $\left(\Phi=0^{\circ}, 10^{\circ}, 20^{\circ}\right.$, and $30^{\circ} ; \Phi=40^{\circ}$ and $45^{\circ}$ ) were 280 and $330 \mu \mathrm{m}$, respectively

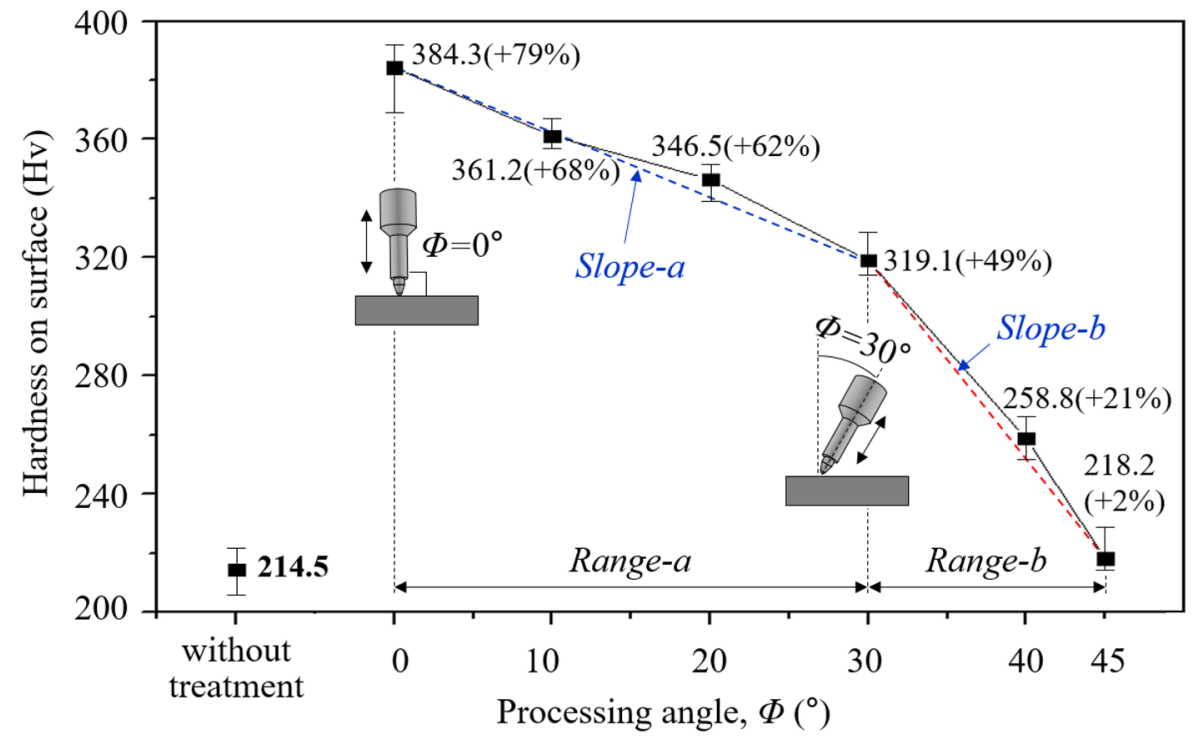

(a)

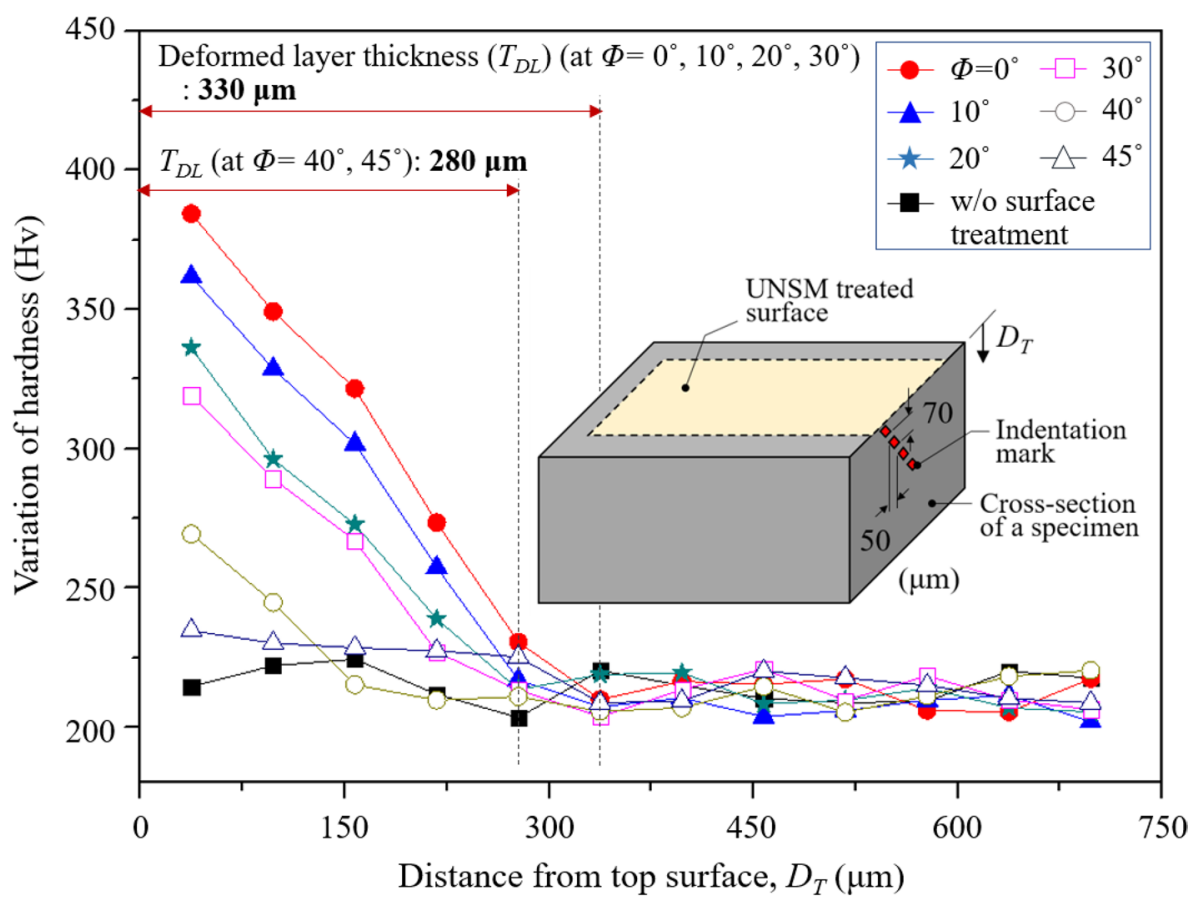

(b) vertically. In the specimen tested, the initial average roughness, $R a_{a v g}$ of the S45C plate was approximately 2.47 and $2.53 \mu \mathrm{m}$ in each direction of $D_{P}$ and $D_{V}$, respectively. The surface roughness profiles after a treatment at each $\Phi=0^{\circ}$ and $45^{\circ}$ are compared in Fig. 5b. Repetitive peaks with a gap of $50 \mu \mathrm{m}$ were observed along $D_{V}$, which were of the same value as that of the line interval, $d_{f}$ shown in Table 1. Furthermore, the peak height was increased by more than two times, and the average value of $R a$ was approximately 22.5 times greater at $\Phi=45^{\circ}$ along $D_{V}$, as compared with those at $\Phi=0^{\circ}$. The dotted red line in Fig. $5 \mathrm{~b}$ is the measured roughness profile of the initial state of the specimen. Compared with the roughness profiles before and after the UNSM along $D_{P}$ and $D_{V}$, the roughness after UNSM with $\Phi=0^{\circ}$ reduced to approximately 2.3 and $2.1 \mu \mathrm{m}\left(-\Delta R a_{a v g}\right)$, respectively; however, the profile after treatment at $\Phi=45^{\circ}$ along $D_{V}$ became rougher with the amount of approximately $2.2 \mu \mathrm{m}\left(+\Delta R a_{a v g}\right)$, as shown in Figs. 5a, b. And, a non-contact surface profilometer (Newview-7300, Zygo, USA) was used to measure a surface morphology. Figure 6 shows the 


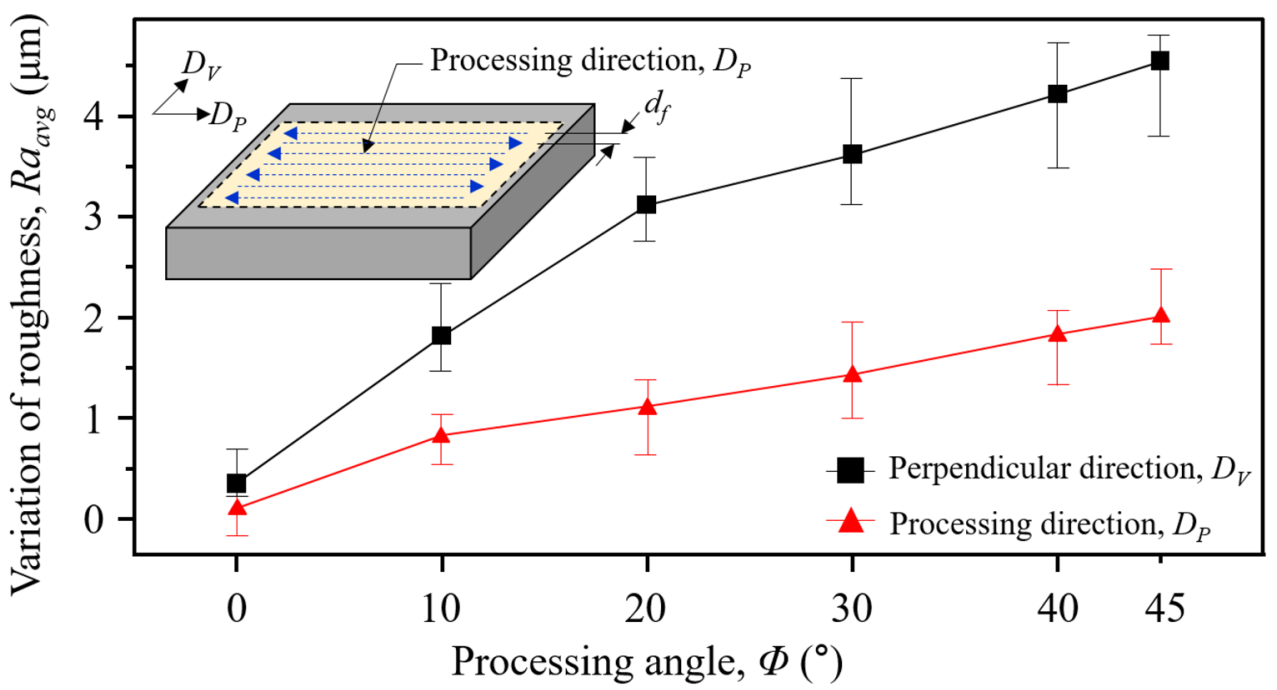

(a)

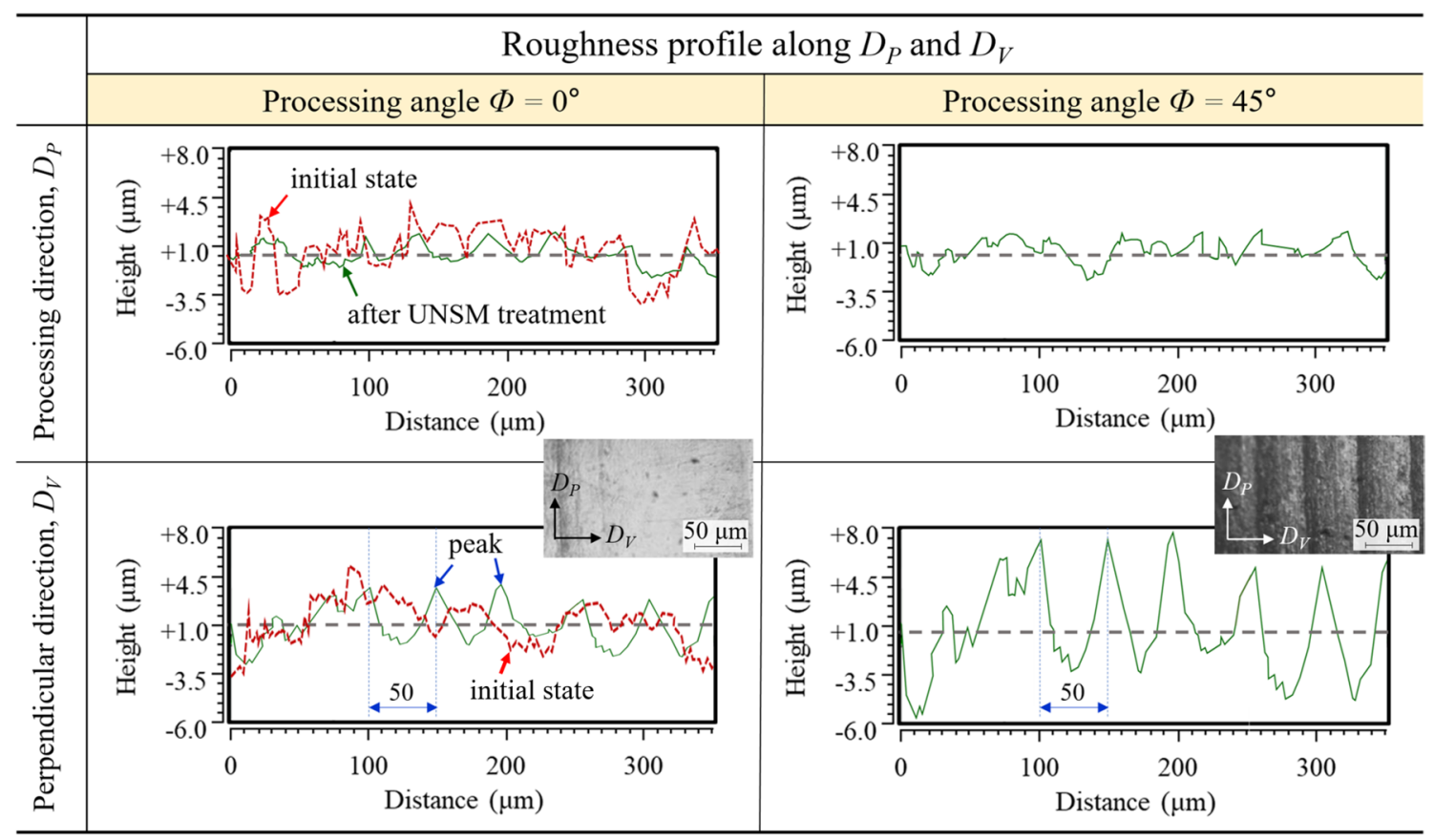

(b)

Fig. 5 Roughness variation along two directions $D_{P}$ and $D_{V}$ on the surface; a average roughness versus change in processing angle, $\Phi$ along the two directions; the roughness increased with $\mathrm{f} \Phi$. b Each roughness profile at $\Phi$ of $0^{\circ}$ and $45^{\circ}$, and the dotted red lines show

measured results of surface morphology after UNSM treatment with $\Phi=0^{\circ}$ and $45^{\circ}$. For $\Phi=0^{\circ}$ and $45^{\circ}$, the height to the peak in each case was 10.72 and $9.21 \mu \mathrm{m}$, respectively.

To observe the variation in the microstructure of a specimen after the surface treatment, its cross section was the roughness profiles in the initial state of the specimen. Along the $D_{V}$ direction, roughness peaks were generated regularly owing to the line interval, $d_{f}(=50 \mu \mathrm{m})$ depicted in Table 1

captured using an optical microscope (MA200, Nikon, Japan) after etching for $15 \mathrm{~s}$ using an etchant mixed with ethanol $(100 \mathrm{ml})$ and hydrogen chloride $(\mathrm{HCl}, 12 \mathrm{ml})$. As shown in the top images of Fig. 7, plastic deformation and grain refinement occurred at the upper part after the UNSM. 


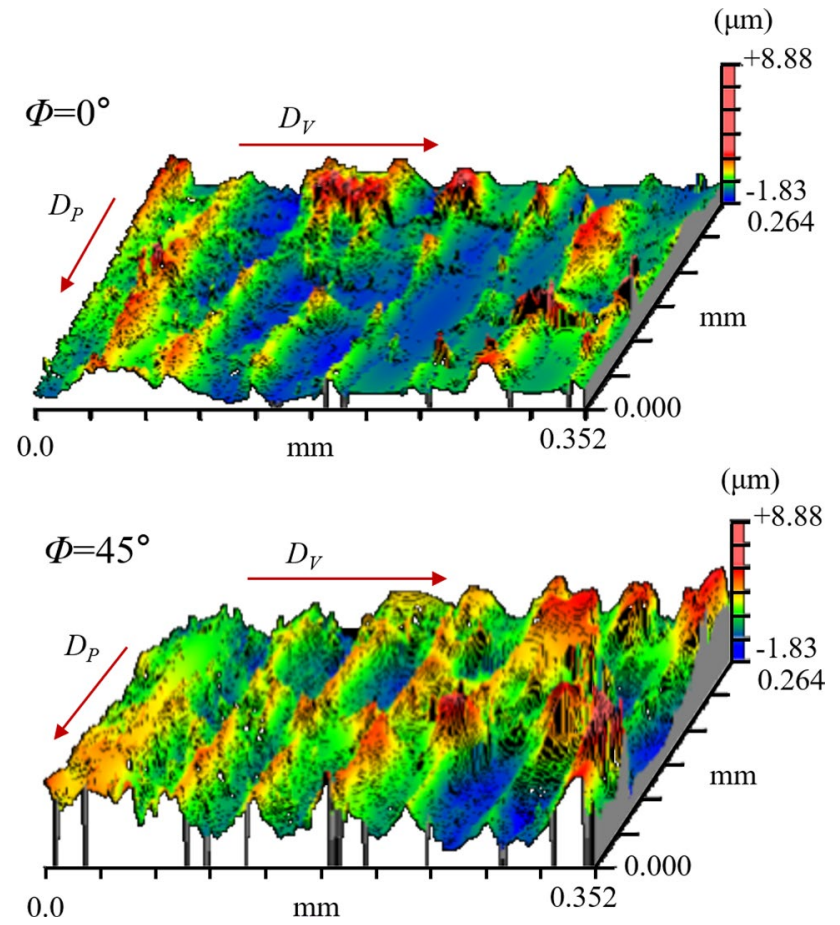

Fig. 6 Surface morphology of UNSM treated surface; each morphology profile was obtained at the $\Phi$ of $0^{\circ}$ (upper) and $45^{\circ}$ (bottom)
In addition, electron backscatter diffraction (EBSD) images were used to compare the quantitative change in deformation (deformed layer thickness, $T_{D L}$ ) at three cases of $\Phi \mathrm{s}$ (see the lower images in Fig. 7). When the $\Phi$ s were $0^{\circ}, 30^{\circ}$, and $45^{\circ}$, the $T_{D L}$ was approximately 343,294 , and $253 \mu \mathrm{m}$, respectively. Among the three $\Phi$ conditions, $T_{D L}$ was the largest at approximately $343 \mu \mathrm{m}$ under a $\Phi$ of $0^{\circ}$, and the amount of $T_{D L}$ decreased with an increase in $\Phi$. This can be explained based on Eq. (2) and Fig. 2. The striking force, $F_{\text {tilting }}$ depends on $\Phi$; therefore, we verified that the input energy for the plastic deformation of the treated surface diminished with an increase in $\Phi$. Additionally, the striking force applied on the surface affected the plastic deformation in the thickness direction $\left(D_{T}\right)$, and gain refinement occurred densely near the top surface, which gradually changed coarsely in the thickness direction. Using this mechanism, the gradient material properties can be obtained along the thickness direction.

\subsection{Generation of Hardness Gradient on Metal Surface}

To evaluate the usefulness of this study, UNSM surface treatment was conducted individually on nine zones measuring $30 \mathrm{~mm} \times 30 \mathrm{~mm}$ on a S45C plate, as shown in Fig. $8 \mathrm{a}$. Five different $\Phi$ s of $0^{\circ}, 20^{\circ}, 30^{\circ}, 40^{\circ}$, and $45^{\circ}$ were utilized in the surface treatment with the same process parameters,

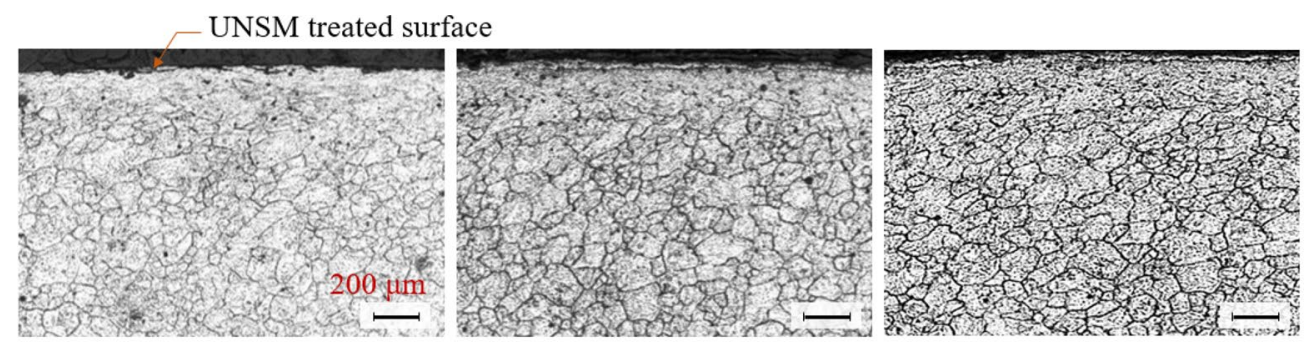

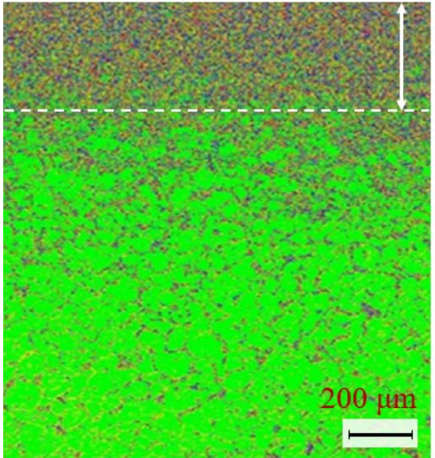

Processing angle, $\Phi=0^{\circ}$ $T_{D L}=343 \mu \mathrm{m}$

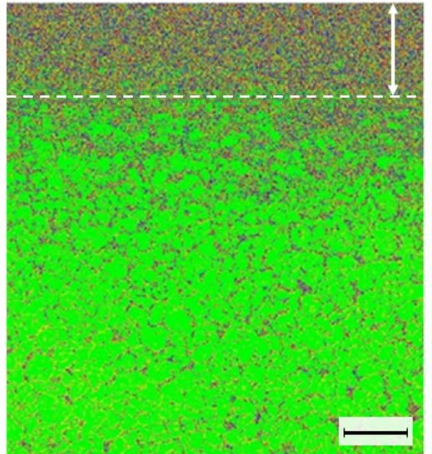

$\Phi=30^{\circ}$

$T_{D L}=294 \mu \mathrm{m}$

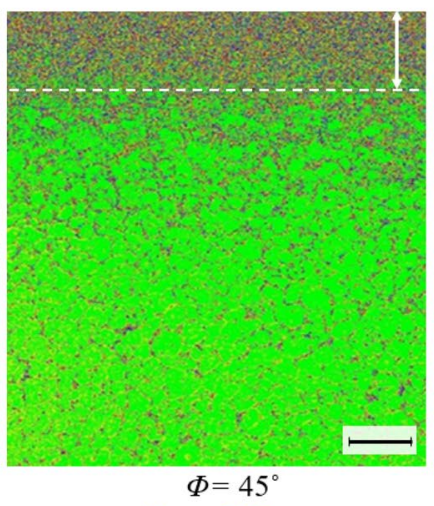

$T_{D L}=253 \mu \mathrm{m}$
Deformed

layer thickness, $T_{D L}$
Fig. 7 Cross-sectional images of UNSM treated surface; optical microscopy images obtained at three processing angles $\Phi$ of $0^{\circ}, 30^{\circ}$, and $45^{\circ}$ (upper), and electron backscatter diffraction (EBSD) images at three $\Phi$ values (lower). $T_{D L}$ denotes the deformed layer thickness after UNSM; with increasing $\Phi, T_{D L}$ decreased (scale bar $=200 \mu \mathrm{m}$ ) 
Fig. 8 Generation of local hardness by controlling $\Phi$ in the UNSM; a nine rectangular sections measuring $30 \mathrm{~mm} \times 30 \mathrm{~mm}$ treated with various $\Phi_{\mathrm{S}}$ from $0^{\circ}, 20^{\circ}, 30^{\circ}$, $40^{\circ}$, to $45^{\circ}$, and $\mathbf{b}$ measured hardness changes along three tracking lines, denoted Line-1, -2 , and -3 in Fig. $7 \mathbf{a}$, which pass through three sections of $\alpha$-zone, $\beta$-zone, and $\gamma$-zone, respectively. $\Delta \mathrm{Hv}$ denotes the hardness change at the interface zones

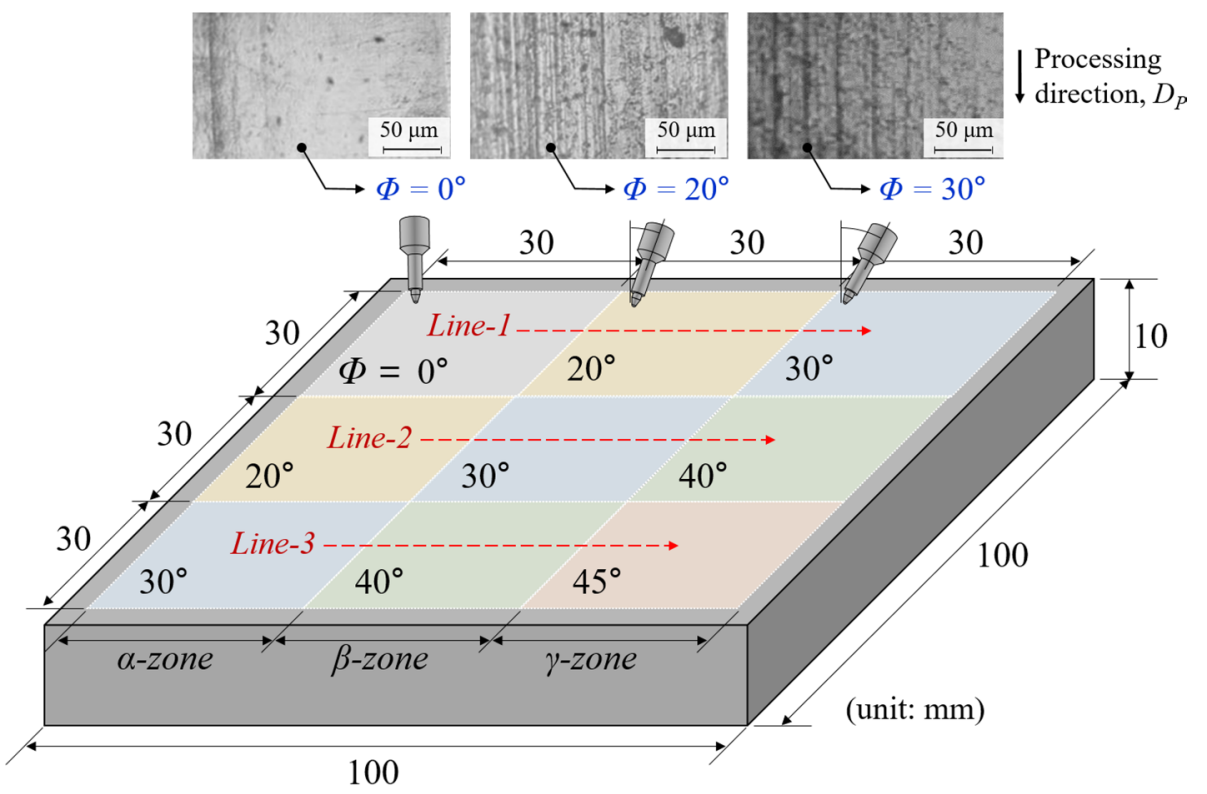

(a)

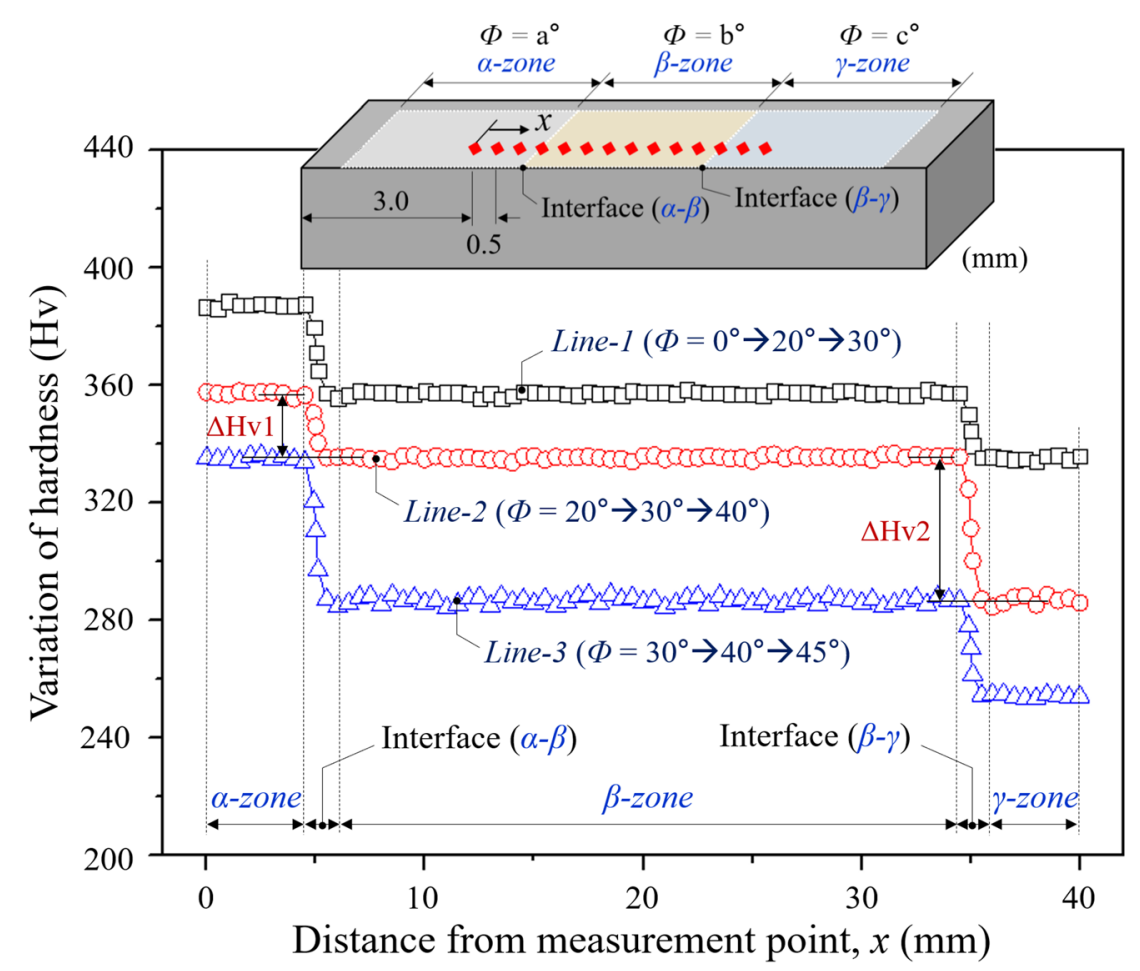

(b) i.e., $P_{s t}$ of $50 \mathrm{~N}, v_{f}$ of $1500 \mathrm{~mm} / \mathrm{min}, d_{f}$ of $50 \mu \mathrm{m}$, and $f$ of $20 \mathrm{kHz}$, as mentioned in Sect. 3.1. After each local treatment, we measured the hardness distribution along three lines, i.e., Line-1, Line-2, and Line-3, as depicted in Fig. 8a. Each measurement line contains three zones in the following order: $\alpha$-, $\beta$-, and $\gamma$-zones. Line- 1 passes through zones treated with $\Phi=0^{\circ}, 20^{\circ}$, and $30^{\circ}$; Line-2 passes through $\Phi=20^{\circ}, 30^{\circ}$, and $40^{\circ}$ zones; Line- 3 passes through $\Phi=30^{\circ}$, $40^{\circ}$, and $45^{\circ}$ zones. Furthermore, each measurement line passes two interfaces between $\alpha$ - and $\beta$-zones as well as $\beta$ - and $\gamma$-zones, and the width of interface is less than 2 to $3 \mathrm{~mm}$.

The hardness along the lines was measured at 80 points with a space of $0.5 \mathrm{~mm}$ between points. Figure $8 \mathrm{~b}$ summarizes the change in hardness of each line. As mentioned previously, the hardness changed depending on $\Phi$; it was 
observed that the hardness was uniform within each zone but changed significantly between zones. However, the change in hardness $(\Delta \mathrm{Hv})$ in two interfaces was different despite the same change in $\Delta \Phi$, as shown in Line-2 of Fig. 8b. Both interfaces $(\alpha-\beta)$ and $(\beta-\gamma)$ in Line-2 has the same change of $\Delta \Phi=10^{\circ}$, but the variation of hardness in interface $(\beta$ $\gamma)$ were 2.1 times larger than that in $(\alpha-\beta)$ due to different slopes of hardness change as shown in Fig. 4a. Through these results, it has been proved that the hardness varies according to the change of $\Phi$. In order to understand the effect of surface treatment with different $\Phi$ s on an arbitraryshaped metal surface, we applied this approach on the surface of a hemisphere. The processing angle $\left(\Phi_{\text {h.s. }}\right)$ on a hemisphere can be calculated using Eq. (3) and the schematic illustration in Fig. 9:

$\Phi_{h . s .}=\tan ^{-1}\left(R_{z} / h_{z}\right)$,

where $R_{z}$ and $h_{z}$ denote the distance in the radius direction and the height at a location during the surface treatment, respectively. Two types of surface treatments were applied on a hemisphere with a diameter of $80 \mathrm{~mm}$ along the horizontal and vertical directions, as shown in Figs. 10a, b. As shown in Fig. 10a, the first surface treatment (Sect. 1) was performed horizontally with $5 \mathrm{~mm}$ away from the top of the hemisphere, and the second treatment, as shown in Fig. 10b, was conducted vertically on the curved surface at a horizontal width of $2 \mathrm{~mm}$. Subsequently, other treatments from Sect. 2 to 4 were performed in the same manner. The processing conditions of the UNSM were based on the abovementioned parameters. The hardness was measured at ten arbitrary points in each section, and the results are shown in Fig. 10a. The processing angle on each section was calculated using Eq. (3), denoted $\Phi_{\text {h.s. }}=8.2^{\circ}, 19.1^{\circ}, 30.2^{\circ}$, and $42.8^{\circ}$.

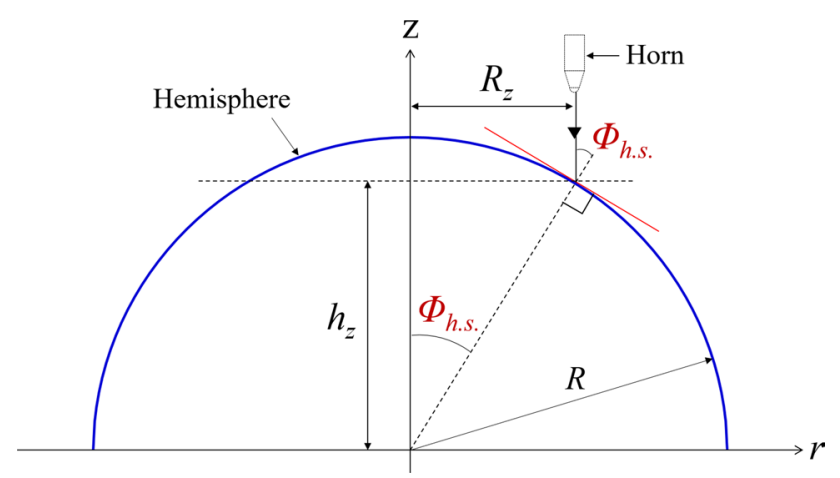

Fig. 9 Method for calculating the processing angle $\Phi$ at a position on the hemisphere with a radius of $R$. If the position of the UNSM horn is known by $h_{z}$ and $R_{z}$, the processing angle can be obtained using Eq. (3)
As expected, the hardness decreased with an increase in $\Phi_{h . s .}$, and the deviation in hardness in the same section increased slightly with an increase in $\Phi_{h . s .}$. The insets of Fig. 10a, b show the optical microscope images in each section, and some stripes generated by the line interval $d_{f}$ can be observed along the processing direction, $D_{P}$. The variation in hardness was shown along a vertically treated line on the hemisphere, as shown in Fig. 10b. Along the line tracking $d_{c}$ from $\mathrm{O}$ to $\mathrm{P}$, the hardness measured every $1 \mathrm{~mm}$ decreased continuously owing to a steady increase in $\Phi_{h . s .}$. Therefore, a hardness gradient surface was generated by a steady and gradual control of $\Phi_{h . s}$ using the proposed method.

In order to analyze the friction and wear characteristics after UNSM treatment under conditions of $\Phi=0^{\circ}$ and $45^{\circ}$, a ball-on-disk (RB-101-MP, R\&B Co. Ltd., Korea) wear test has been conducted at $100 \mathrm{rpm}$ for $600 \mathrm{sec}$. After the test, wear width and depth were measured quantitatively using a stylus profilometer (Form Talysurf series 2, Taylor Hobson, U.K.) for each case. The wear width and depth were dramatically reduced from 7.3 to $3.6 \mathrm{~mm}$ and 0.225 to $0.04 \mathrm{~mm}$, respectively, when the UNSM was treated on the surface. Also, the processing angle of UNSM affected the amount of wear slightly, as shown in Fig. 11.

\section{Conclusions}

The control of local surface hardness using UNSM by changing the processing angle $\Phi$ was investigated in this study. To evaluate the treatment effect, the surface hardness was measured and the microstructure change was analyzed using optical microscopy and EBSD images. Furthermore, to observe the change in the thickness direction, the specimen was cut into cross sections and then the hardness was measured along the thickness direction. We discovered that the surface hardness increased by local plastic deformations and grain refinements on the surface after UNSM, and the amount of hardness increase was the largest at $\Phi=0^{\circ}$, which decreased gradually by an increase in $\Phi$. This can be explained based on the change in the striking force, $F_{\text {tilting }}$ according to $\Phi$, as shown in Eq. (2).

For $\Phi$ exceeding $30^{\circ}$, which was the critical degree in hardness change, the hardness increase decreased significantly owing to the insufficient striking force. Furthermore, based on the hardness in the thickness direction and the microstructure data, the average deformed layer was reached approximately $345 \mu \mathrm{m}$ at a $\Phi$ of $0^{\circ}$, and it was approximately $253 \mu \mathrm{m}$ at a $\Phi$ of $45^{\circ}$. Therefore, it was verified that the hardness gradient can be controlled in the thickness direction. S45C specimens having flat and hemisphere shapes were utilized to conduct the UNSM with various $\Phi$ values to verify the usefulness of the proposed method. In conclusion, it was experimentally verified that the surface 
Fig. 10 a Hardness variation on a hemisphere of diameter $(D)$ $80 \mathrm{~mm}$ that was treated with UNSM under different processing angles $\Phi$ of $8.2^{\circ}, 19.1^{\circ}$,

$30.3^{\circ}$, and $42.8^{\circ}$. Optical microscope images show each treated surface morphology. The horn was striking vertically on the inclined surface of each section to generate circle patterns with a line interval $\left(d_{f}\right.$, as defined in Table 1) of $50 \mu \mathrm{m}$ until a horizontal width of $2 \mathrm{~mm}$ was achieved. b Hardness variation along a circular arc from point $\mathrm{O}$ to P. UNSM was conducted on the arc with a $d_{f}$ of $50 \mu \mathrm{m}$ to achieve a width of $2 \mathrm{~mm}$

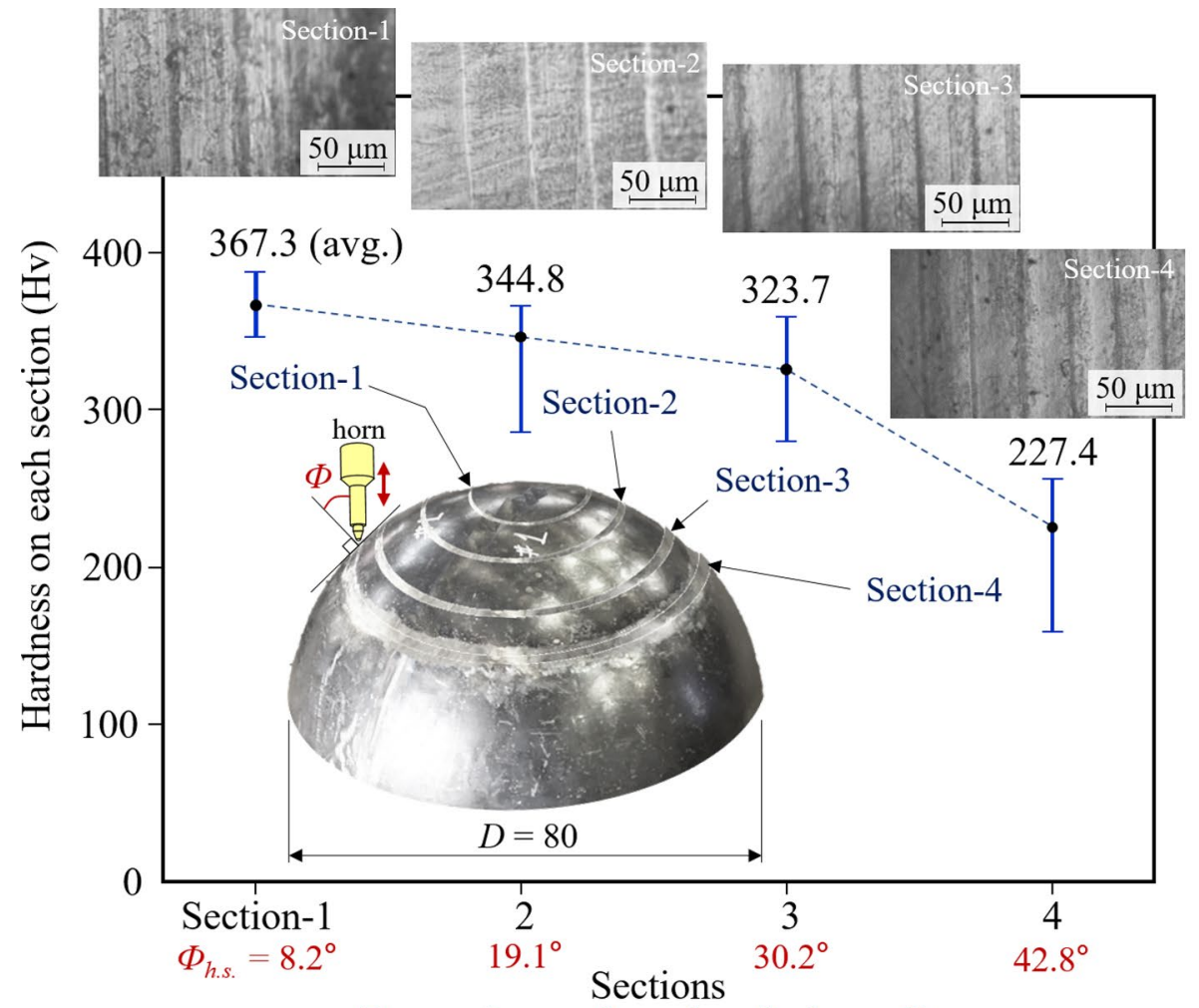

Processing angle on hemisphere, $\Phi_{h . s .}$

(a)

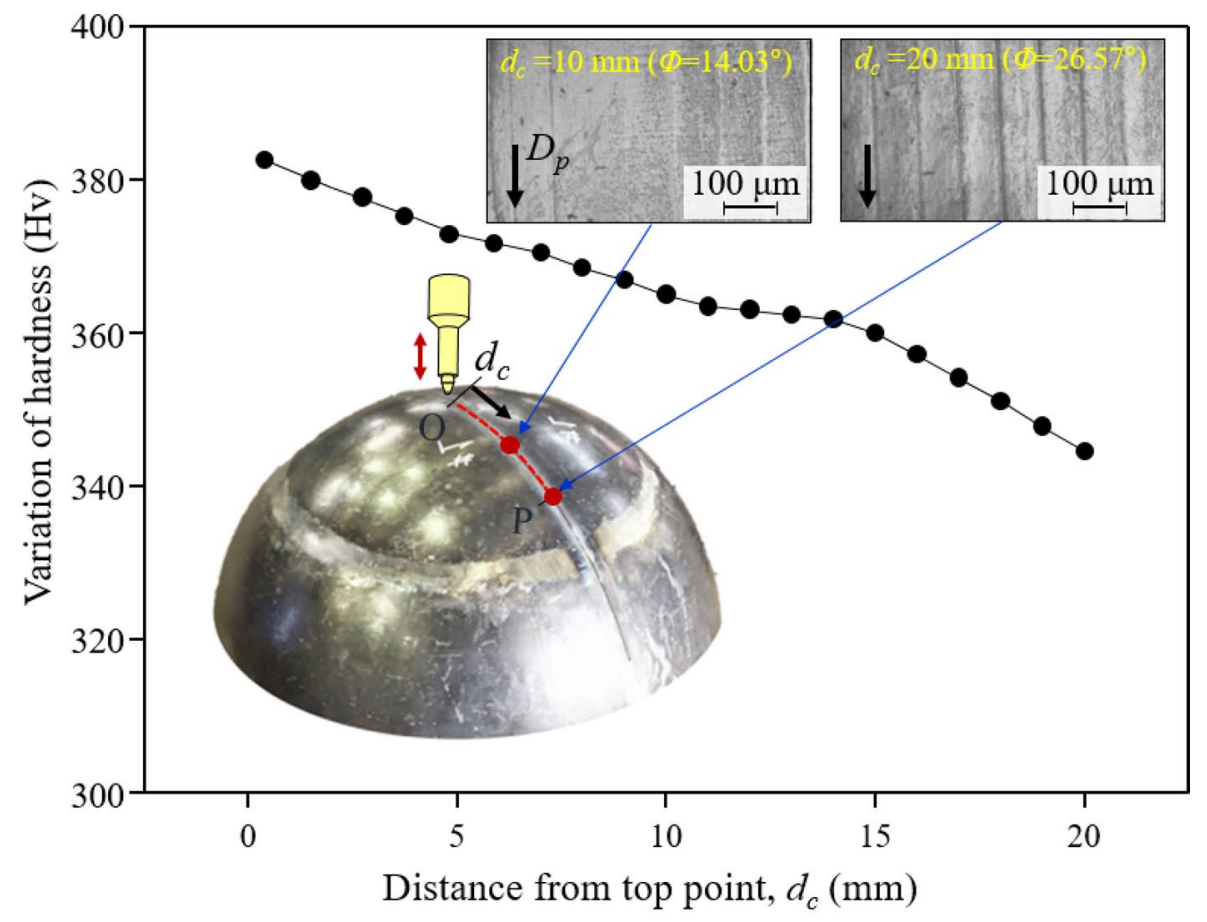

(b) 
Fig. 11 Comparison of ball-disc wear test results with and without UNSM treatment

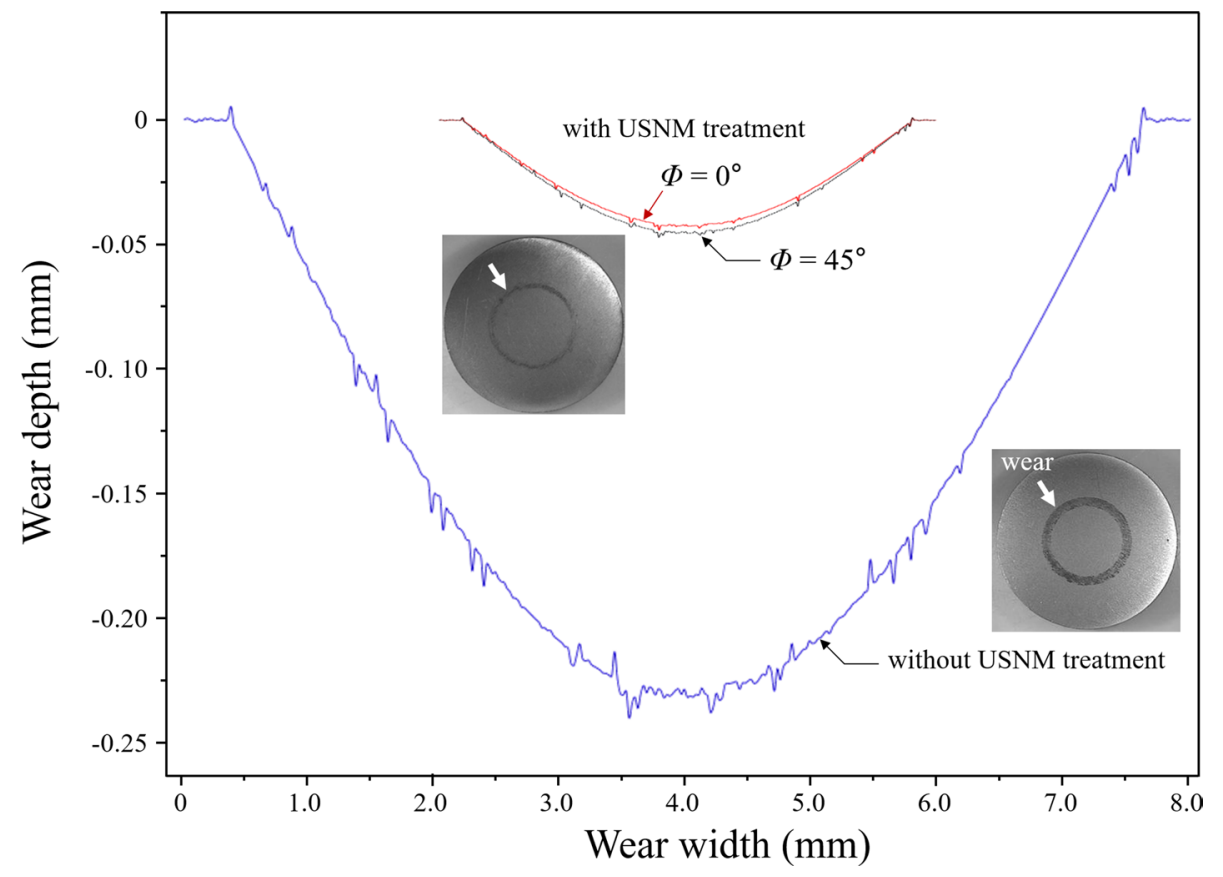

hardness increased from $2.0-49.2 \%$ after the treatment with various $\Phi_{\mathrm{s}}$, compared with that of the initial state. Therefore, we believe that this approach is effective for changing the local hardness gradient and surface morphology of various mechanical parts were used in wear resistance.

Acknowledgements This work was supported by the National Research Foundation of Korea (NRF) grant funded by the Korea government (MSIT) (No. 2019R1A5A808320112), and also was granted financial support from the Technology Innovation Program (20000201) funded by the Ministry of Trade, Industry \& Energy (MOTIE, Korea).

Open Access This article is licensed under a Creative Commons Attribution 4.0 International License, which permits use, sharing, adaptation, distribution and reproduction in any medium or format, as long as you give appropriate credit to the original author(s) and the source, provide a link to the Creative Commons licence, and indicate if changes were made. The images or other third party material in this article are included in the article's Creative Commons licence, unless indicated otherwise in a credit line to the material. If material is not included in the article's Creative Commons licence and your intended use is not permitted by statutory regulation or exceeds the permitted use, you will need to obtain permission directly from the copyright holder. To view a copy of this licence, visit http://creativecommons.org/licenses/by/4.0/.

\section{References}

1. Tran, H. N., Oh, H. S., Hong, S. T., Han, H. N., Cao, J., Ahn, S. H., \& Chun, D. M. (2015). A review of electrically-assisted manufacturing. International Journal of Precision Engineering and Manufacturing-Green Technology, 2(4), 365-376.

2. Seong, M. H., Lee, J. S., Hwang, I. S., \& Jeong, H. E. (2019). Significant adhesion enhancement of bioinspired dry adhesives by simple thermal treatment. International Journal of Precision Engineering and Manufacturing-Green Technology, 6, 587-599.

3. Vaezi, M. R., Sadrnezhaad, S. K., \& Nikzad, L. (2008). Electrodeposition of $\mathrm{Ni}-\mathrm{SiC}$ nano-composite coatings and evaluation of wear and corrosion resistance and electroplating characteristics. Colloids and Surfaces A, Physicochemical and Engineering Aspects, 315(1-3), 176-182.

4. Arab Juneghani, M., Farzam, M., \& Zohdirad, H. (2013). Wear and corrosion resistance and electroplating characteristics of electrodeposited $\mathrm{Cr}-\mathrm{SiC}$ nano-composite coatings. Transactions of Nonferrous Metals Society of China, 23, 1993-2001.

5. Benea, L., Bonora, P. L., Borello, A., \& Martelli, S., (2002) Wear corrosion properties of nano-structured $\mathrm{SiC}-$ nickel composite coatings obtained by electroplating, Wear, 249, 995-1003.

6. Godec, M., Donik, C., Kocijan, A., Podgornik, B., \& Skobir Balantič, D. A. (2020). Effect of post-treated low-temperature plasma nitriding on the wear and corrosion resistance of $316 \mathrm{~L}$ stainless steel manufactured by laser powder-bed fusion. Additive Manufacturing, 32, 101000. .

7. Brownlie, F., Hodgkiess, T., Pearson, A., \& Galloway, A. M. (2017). Effect of nitriding on the corrosive wear performance of a single and double layer Stellite 6 weld cladding. Wear, 376-377, 1279-1285.

8. Menthe, E., Rie, \& K. T. (1999). Plasma nitriding and plasma nitrocarburizing of electroplated hard chromium to increase the wear and the corrosion properties. Surface and Coatings Technology, 112, 217-220.

9. Park, G. Y., Kim, H. S., \& Lee, B. Y. (2020). Surface Assembly Strategy for the Fabrication of $\mathrm{MoS}_{2}$ thin-film patterns. International Journal of Precision Engineering and Manufacturing, 20, 2215-2220.

10. Kong, D., Zhao, W., \& Zhang, L. (2019). Friction wear behaviors of chemical vapor deposited diamond films at high temperatures. Journal of Superhard Materials, 41, 98-105.

11. Yana, G., Wu, Y., Cristea, D., Liu, L., Tierean, M., Wang, Y., Lu, F., Wang, H., Yuan, Z., Munteanu, D., \& Zhao, D. (2019). Mechanical properties and wear behavior of multi-layer 
diamond films deposited by hot-filament chemical vapor deposition. Applied Surface Science, 494, 401-411.

12. Menezes, M. R., Godoy, C., Buono, V. T. L., Schvartzman, M. M. M., \& Wilson, J. C. A. (2017). Effect of shot peening and treatment temperature on wear and corrosion resistance of sequentially plasma treated AIS I 316L steel. Surface and Coatings Technology, 309, 651-662.

13. González, J., Peral, L. B., Zafra, A., \& Pariente, I. F. (2019). Influence of shot peening treatment in erosion wear behavior of high chromium white cast iron. Metals, 9, 933.

14. Avcu, Y., Yetik, O., Koçoğlu, H., Avcuc, E., \& Sınmazçelik, T. (2018). Dry sliding wear behaviour of shot peened TI6AL4V alloys at different peening times. Acta Physica Polonica A, 134, 349-353.

15. Kubiak, K., Fouvry, S., Marechal, A. M., \& Vernet, J. M. (2006). Behaviour of shot peening combined with WC-Co HVOF coating under complex fretting wear and fretting fatigue loading conditions. Surface and Coatings Technology, 201, 4323-4328. .

16. Jinoop, A. N., Subbu, K., \& Paul, S. C. P., \& Palani, I. A.,(2019) Post-processing of laser additive manufactured inconel 718 using laser shock peening, International Journal of Precision Engineering and Manufacturing, 20, 1621-1628.

17. Zhou, J., Sun, Y., Huang, S., Sheng, J., Li, J., \& Boateng, E. A. (2019). Effect of laser peening on friction and wear behavior of medical Ti6Al4V alloy. Optics \& Laser Technology, 109, 263-269.

18. Yin, M., Cai, Z., Li, Z., Zhou, Z., Wang, W., \& He, W. (2019). Improving impact wear resistance of $\mathrm{Ti}-6 \mathrm{Al}-4 \mathrm{~V}$ alloy treated by laser shock peening. Transactions of Nonferrous Metals Society of China, 29, 1439-1448. .

19. Dai, F. Z., Geng, J., Tan, W. S., Ren, X. D., Lu, J. Z., \& Huang, S. (2018). Friction and wear on laser textured Ti6Al4V surface subjected to laser shock peening with contacting foil. Optics \& Laser Technology, 103, 142-150. .

20. Xing, Ge. M. Z., Tang, J. Y., Ye, Y., Fan, X., \& Lu, Z. Y. L., \& Zhang, X.H., (2018) Wear behavior of Mg-3Al-1Zn alloy subjected to laser shock peening, Surface and Coatings Technology, 337, 501-509.

21. Jamkamon, K., Yamada, K., Inoue, T., Sekiya, K., \& Tanaka, R. (2019). Improved machinability of high hardened die steel by using pulsed laser surface treatment. International Journal of Precision Engineering and Manufacturing, 20, 1667-1676. .

22. Kaushik, N. C., \& Rao, R. N. (2016). The effect of wear parameters and heat treatment on two body brasive wear of Al-SiC-Gr hybrid composites. Tribology International, 96, 184-190.

23. Vashishtha, N., Sapate, S. G., Bagde, P., \& Rathod, A. B. (2016). Effect of heat treatment on friction and abrasive wear behaviour of WC-12Co and $\mathrm{Cr} 3 \mathrm{C} 2-25 \mathrm{NiCr}$ coatings. Tribology International, 118, 381-399.

24. Straffelini, G., Verma, P. C., Metinoz, I., Ciudin, R., Perricone, G., \& Gialanella, S. (2016). Wear behavior of a low metallic friction material dry sliding against a cast iron disc: Role of the heattreatment of the disc. Wear, 348-349, 10-16.

25. Kim, D.-H., Kim, J.-H., Kim, Y.-G., Lim, J.-H., Park, H.-J., \& Ye, B.-J., (2018) Evaluation of microstructure and mechanical properties on solution heat treatment of recycled A319 cutting chip, International Journal of Precision Engineering and Manufacturing-Green Technology, 5(3), 427-433.

26. Lee, Y., Park, S., Byun, C., \& Lee, S.-K., (2018) Liquid cooling of laser-driven head light employing heat spreader manufactured by 3D metal printing, International Journal of Precision Engineering and Manufacturing-Green Technology, 5(2), 295-301.

27. Tripathi, K., Gyawali, G., Amanov, A., \& Lee, S. W. (2017). Synergy effect of ultrasonic nanocrystalline surface modification and laser surface texturing on friction and wear behavior of graphite cast iron. Tribology Transactions, 60(2), 226-237.
28. Ma, C., Andani, M. T., Qin, H., Moghaddam, N. S., Ibrahim, H., Jahadakbar, A., Amerinatanzi, A., Ren, Z., Zhang, H., Doll, G. L., Dong, Y., Elahinia, M., \& Ye, C. (2017). Improving surface finish and wear resistance of additive manufactured nickel-titanium by ultrasonic nano-crystal surface modification. Journal of Materials Processing Technology, 249, 433-440.

29. Chang, S. K., Pyun, Y. S., \& Amanov, A. (2015). Wear and chattering characteristics of rail materials by ultrasonic nanocrystal surface modification. International Journal of Precision Engineering and Manufacturing, 16, 2403-2410. .

30. Pyun, Y. S., Cho, I. H., Suh, C. M., Park, J., Rogers, J., Kayumov, R., \& Murakami, R. (2013). Reducing production loss by prolonging service life of rolling mill shear pin with ultrasonic nanocrystal surface modification technology. International Journal of Precision Engineering and Manufacturing, 14, 2027-2232.

31. Ye, C., Telang, A., Gill, A. S., Suslov, S., Idell, Y., Zweiacker, K., Wiezorek, J. M. K., Zhou, Z., Qian, D., Ramaiah Mannava, S., \& Vasudevan, V. K. (2014). Gradient nanostructure and residual stresses induced by ultrasonic nano-crystal surface modification in 304 austenitic stainless steel for high strength and high ductility. Materials Science and Engineering, A, 613, 274-288. .

Publisher's Note Springer Nature remains neutral with regard to jurisdictional claims in published maps and institutional affiliations.

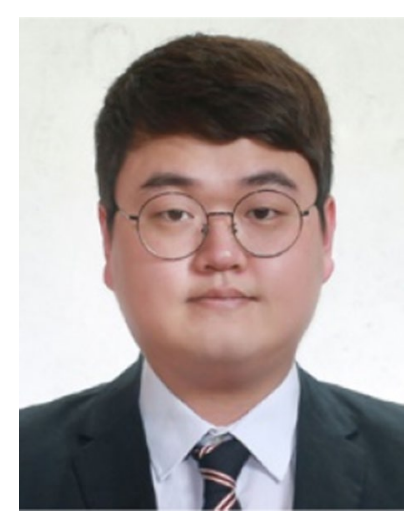

Yeong Kwan Jo is a currently Ph.D. course student in the School of mechanical engineering at Pusan National University. His research topics are development of cladding process and its application to surface mechanical characteristics.

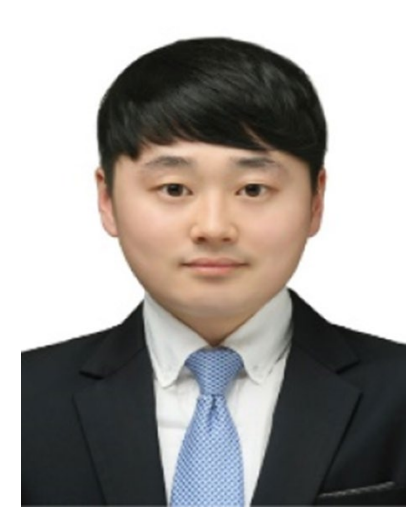

Yeong Wook Gil is a master course student in the School of mechanical engineering at Pusan National University. He earned his Master in manufacturing system engineering at Pusan Nation University in 2020. His research fields are the engineering for surface treatment process using ultrasonic nano-crystal surface modification. 


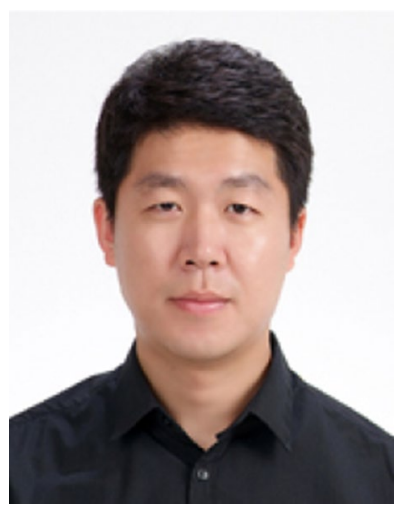

Do Sik Shim received Ph.D. in Mechanical Engineering from KAIST, Korea in 2010. He has been an assistant professor at Korea Maritime and Ocean University (KMOU) since 2017. His research interests include incremental and roll forming for sheet metal, direct energy deposition (DED) and structural analysis as well as optimal design.

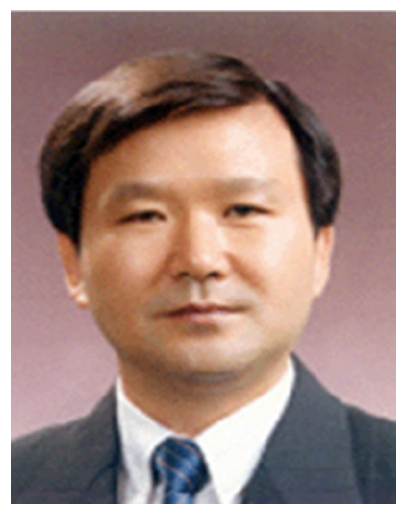

Young Sik Pyun is a professor in department of mechanical engineering at Pusan National University. He earned his Ph.D. in manufacturing system engineering at Korea Advanced Institute of Science and Technology (KAIST) in 1993. His research fields are the engineering for surface treatment process using ultrasonic nano-crystal surface modification.

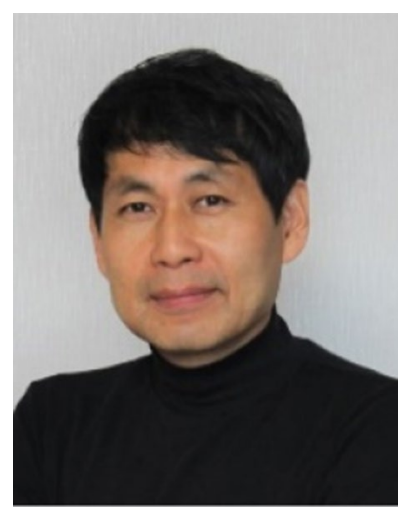

Sang Hu Park is a professor in school of mechanical engineering at Pusan National University. He earned his M.S. and Ph.D. in mechanical engineering at Korea Advanced Institute of Science and Technology (KAIST) in 1996 and 2006, respectively. His research fields are the engineering for additive manufacturing, sheet metal forming, and nanofabrication. 